Special issue: Re-Design Teaching Design

Article

\section{Catena: Collaboration, Cohesion and Continuity in Design Thinking and Making}

\author{
Lohren Deeg ${ }^{1, *}$, Taylor Metz ${ }^{2}$, Richard Tursky ${ }^{3}$ \\ ${ }^{1}$ Associate Professor of Urban Planning, Ball State University, USA \\ ${ }^{2}$ Assistant Teaching Professor of Landscape Architecture, Ball State University, USA \\ ${ }^{3}$ Assistant Teaching Professor of Architecture, Ball State University, USA \\ * Correspondence: lohren.deeg@ gmail.com
}

Guest Editors: Lohren Deeg, Taylor Metz, Richard Tursky, Ball State University, USA

How to Cite: Deeg, L., Metz, T., Tursky, R. 'Catena: Collaboration, Cohesion and Continuity in Design Thinking and Making'. Architecture_MPS 18, 1 (2020): 3.

DOI: https://doi.org/10.14324/111.444.amps.2020v18i1.003.

Submission date: 3 June 2020; Acceptance date: 12 June 2020; Publication date: 1 October 2020

\section{Peer review:}

This article has been peer-reviewed through the journal's standard double-blind peer review, where both the reviewers and authors are anonymised during review.

\section{Copyright:}

(C) 2020, Lohren Deeg, Taylor Metz and Richard Tursky. This is an open-access article distributed under the terms of the Creative Commons Attribution Licence (CC BY) 4.0 https://creativecommons.org/licenses/by/4.0/, which permits unrestricted use, distribution and reproduction in any medium, provided the original author and source are credited • DOI: https://doi.org/10.14324/111.444.amps.2020v18i1.003.

\section{Open access:}

Architecture_MPS is a peer-reviewed open-access journal.

\begin{abstract}
In the interests of enhanced collaborative methods of design thinking, design communication, representation and rapid ideation, this article examines how a series of related activities and events, 'catenated' together, or forming a 'catena' ${ }^{1}$ of design thinking, could create a clearer, more meaningful and more efficient portfolio of work for a beginning design studio. Drawing inspiration upon the operative verbs found in the work of sculptor Richard Serra, ${ }^{2}$ and using the artefacts from such activities to create generative design products and iterations across a semester schedule, this paper chronicles a series of active in-class collaborations over the course of a semester that allowed a cohort of students to connect a series of design projects together, rather than experience a series of unconnected learning objectives as was typical. References to learning theories including Jerome Bruner's spiral curriculum and David Kolb's theory of experiential learning ${ }^{3}$ informed the inquiry. Student feedback and reflection informed the areas of success and areas of improvement.
\end{abstract}

Keywords: design thinking; design education; learning theory; project-based learning; interdisciplinary learning 


\section{Introduction}

Foundation-level education in environmental design, including fundamentals of design thinking, project-based learning and a studio-based learning environment, have deep roots in the Bauhaus curriculum and in apprenticeships found in the construction trades. In recent years, design educators have examined a variety of ways to teach design to a generation described as 'post-millennial' ${ }^{4}$ This diversity has created a disparate menu of projects and activities that can result in unclear learning objectives, portfolios that lack cohesion and students who may not appreciate the subtleties of design methods and process as communicated by different disciplines that contribute to the constructed environment. Our recent inquiry has led to the following observations.

1. Student learners tend to prefer to perform an activity of design or making only once, and perfectly, for a given deadline. There appears to be a pressure for perfection in the completion of a task, or in verbally answering a question, perhaps informed by the culture of standardized tests which have become ubiquitous across public education in the United States. This testing culture has arguably convinced the learner that there is only one right answer for every inquiry, leaving little to no respect for differing points of view or diversity of backgrounds in a critical thinking discourse. This also creates an undue pressure on the student learner.

2. Learners tend to be distracted by myriads of personal or familial contacts, streaming video or gaming entertainment, and a broad social network established well before college via their mobile devices. This phenomenon makes group discussions silent, the studio class time unproductive and lectures or demonstrations disruptive. It also tends to test the temperament of the instructor.

3. Students are exhibiting a lack of curiosity or critical thinking of why things are the way they are, given the decline of expertise and eroded societal construct of truth versus so-called 'fake news'. These collected phenomena may be contributing to an alarming surge of depression and anxiety in college-age students. ${ }^{6}$

4. The access to free, open, unlimited information via search engines and databases has instituted an attitude of what we shall term digital amnesia, or the tendency to not retain or synthesize new information, as it can be so rapidly accessed with an internet connection.

5. Students tend to share ideas, critiques and processes individually or in small groups of two to six persons, but not in large groups of twelve or more. Students appear to be intimidated by the large group setting for fear of ridicule. Group projects in recent experience resulted in either very successful, even joyful collaboration, or a total breakdown of responsibility and accountability, ending in a litany of hard feelings as expressed in reflective statements and course evaluations.

To address these observations, it was proposed in discussions among the authors that connecting the series of projects, tasks, lessons, skills, readings and demonstrations around a central theme or line of thinking was a desirable move to make a collection of studio projects and explorations more meaningful, informative and relevant to both a student learning experience and their resultant portfolio. A theme of 'catena', defined by the Merriam-Webster dictionary as 'a connected series of related things, ${ }^{7}$ was layered over a number of studio-based projects by the authors with a cohort of thirty-eight undergraduate students. The authors questioned: What if a semester of a beginning design studio could explore a theme or line of thinking that allowed each project to lead into the next?

\section{Inspiration}

The authors began with an exploration of Richard Serra's 'action verbs' ${ }^{8}$ as applied to concepts of circulation and movement with the construction of a sequence for a table tennis ball. Building on the generative ability of verbs to define space, a second project examined two-dimensional and three-dimensional compositions originating from Francis D. K. Ching's taxonomy of ordering principles and organizing systems. ${ }^{9}$ The third project continued this examination by further investigating operative design techniques and typologies through the fabrication of an original chess set at the object scale. The semester closed with applications of cumulative design ideas from the previous projects for a hypothetical installation along a river corridor near campus. Already, the collection of projects chosen 
encouraged exploration from multiple scales, from the hand-held object, to the human-scale environment, to the environmental and ecological conditions of a site. It was the authors' goal to see whether these projects could reinforce each other by means of implementing the principle of the spiral curriculum ${ }^{10}$ and allow learning experiences to build on one another.

\section{Participants}

The participants of this particular study were thirty-eight students enrolled in a 100-level required environmental design studio in the spring semester, the first environmental design studio in the college's foundation-level curriculum. Learning objectives for the studio-based course derive from an oversight committee charged with developing curriculum and suggested pedagogies. These objectives include a sequence of projects pulled from an archive of digital resources and led by members of the team. Co-author Taylor Metz synthesized this in a diagram for the team to understand how the semester's projects addressed the learning objectives (Figure 1).
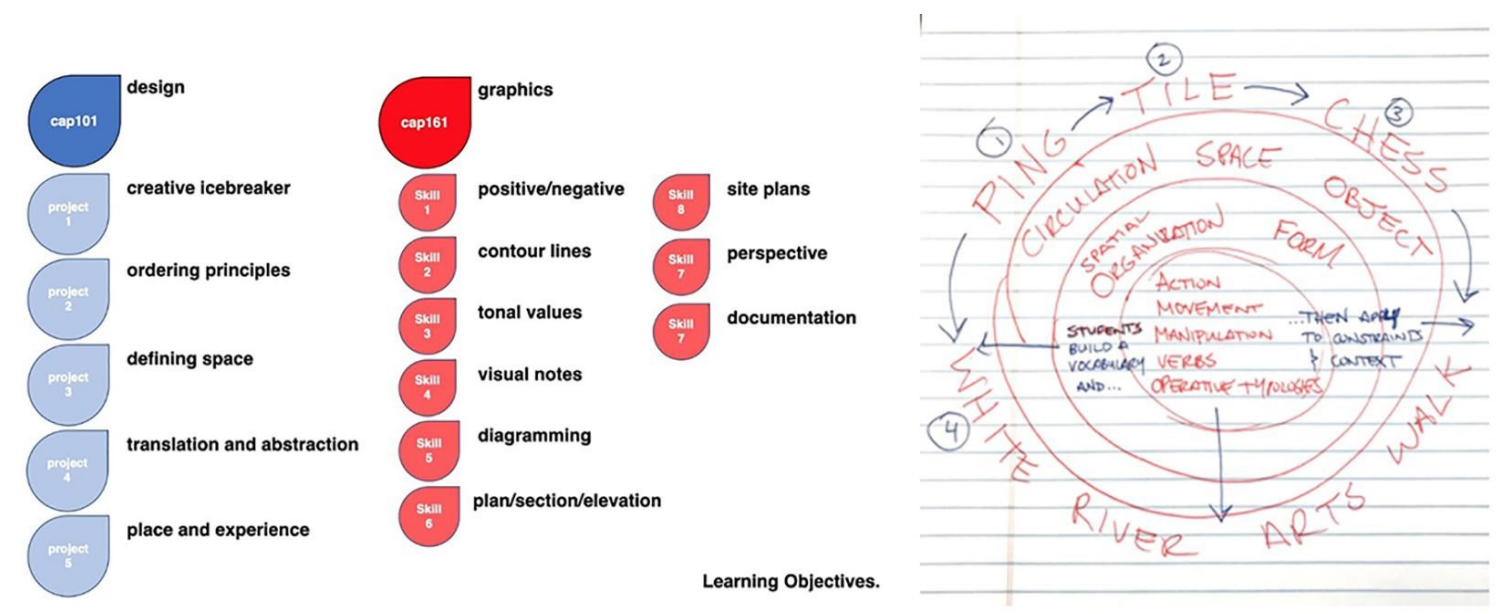

Figure 1 A general visual outline of the learning objectives for two co-requisite introductory courses and part of the common first-year programme at the Estopinal College of Architecture and Planning, and an action diagram for the semester plan (Source: Authors, 2019).

\section{Inquiry}

As the authors observed, due to the collaborative, interdisciplinary and diplomatic approach to curriculum delivery, the library of design projects lacked a certain continuity in portfolios seen in recent years. Projects featured a divergent set of introductions to different issues in sustainability, human-scaled spaces, installations, lighting and urban design. The three professional disciplines in question, while all connected in the construction industry, do carry disparate skillsets, value sets and biases around what a design process is or can be, not to mention the discourse and dogma found across contemporary theories of architecture and city planning. The authors, when assembled into a team, then posited the question: Could each and every project in the semester support or lead into one another, thus forming a logical catena to inspire greater meaning and relevance in the students' minds and resulting portfolios?

\section{Project One: Be the Ball}

Students began the semester by imagining a metaphor of human behaviour and experience through the movement of a table tennis ball. The challenge is embodied into the design of an adventure course with a predetermined amount of corrugated cardboard. It was observed that several students were new to a culture of crafting and making or needed to become familiar with the basics of cutting, measuring and adhesives, as well as the inherent properties and limitations of a material. Limiting the amount of cardboard and allowing no waste also introduced new design criteria to the process, challenging the learner to work within limits, and to find a structural use for all of the material allotted. To relate the exercise to 
human behaviour in the urban context, it was observed that the sport of parkour is arguably changing the perception of urban space and bending societal definitions of human circulation through it. After watching a number of YouTube videos describing the sport, students were tasked with the study of the physical characteristics, abilities and limitations of a table tennis ball as a client, whom the authors named Ping.

\section{Verbs and Actions}

To aid or influence the ball's experience, in addition to gravity, the instructor team elected to use a list of artist Richard Serra's operative verbs ${ }^{11}$ which include such words as roll, crease, fold, store, bend, shorten, twist, dapple, crumple, shave, tear, chip, split, cut and sever. A series of study models were constructed and critiqued, then linked into a final sequence. Preconceived notions of the relationship between form and function were interrogated, as the tendency to decorate projects with unnecessary features was neither encouraged nor allowed. Students were encouraged to concentrate on the spatial sequence and experience of the ball as it travelled. Additional features in the form of mechanical novelties were also encouraged, and students used those opportunities to become competitive with each other as well as push themselves. Drawbridges, elevators, funnels, gears, levers and other features added to the kinetic delight and viewing experience (Figure 2). Drawings in the form of diagramming and elevations allowed for documentation and communication of the design. Spaces and forms were informed by specific ideas of experiences from the perspective of the ball (not the other way around). The use of personification in this instance was intended to inform empathy for the human user in later projects.
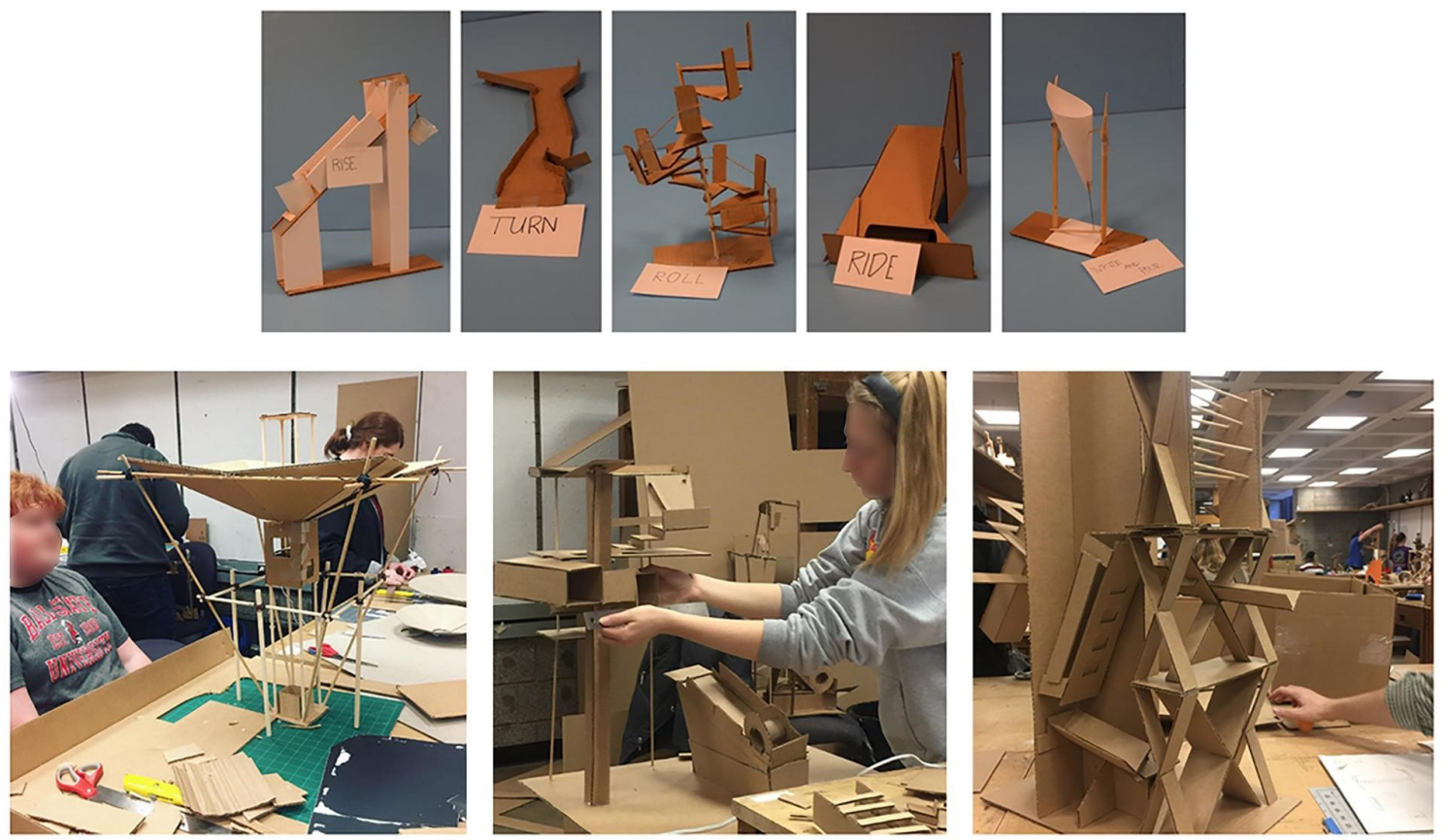

Figure 2 Study models and final designs reflected Richard Serra's operative verbs into experiences and spaces for a standard table tennis ball to circulate through (Source: Authors, 2019).

\section{Project Two: Patterns and Orders Informing Mass and Void}

The second project of the semester afforded exposure to a variety of patterns in the natural and constructed environments, as classified in the taxonomy of organizing systems (centralized, linear, radial, cluster and grid) as written by author Francis D. K. Ching. ${ }^{12}$ Students were challenged to distil and reinterpret sourced photographs, mapping images or architectural drawings through a lens of abstraction and simplification. Simplified images in stark shades of black and white were then manipulated through a selected list of Richard Serra's verbs. Copies of each image, classified as a tile, when repeated, intended to recall the list of spatial ordering systems as shared by Ching, which include axis, symmetry, hierarchy, rhythm, datum and transformation. ${ }^{13}$ Hand-cut, two-dimensional arrays were crafted with 
cardstock and black backing boards, and small three-dimensional models explored spaces as informed by the contrast of mass and void in black and white and provided a review of Richard Serra's operative verbs. Observational skills were enhanced as students explored patterns from the microscopic to celestial scales, and relationships between depictions of positive and negative compositions informed spatial definitions (Figure 3). Different forms of world cities were then explored as a team-building exercise by arranging the individual models around a set of mocked-up geographic characteristics or specific ordinances. Such an exercise communicated early principles of urban form to learners (Figure 4).
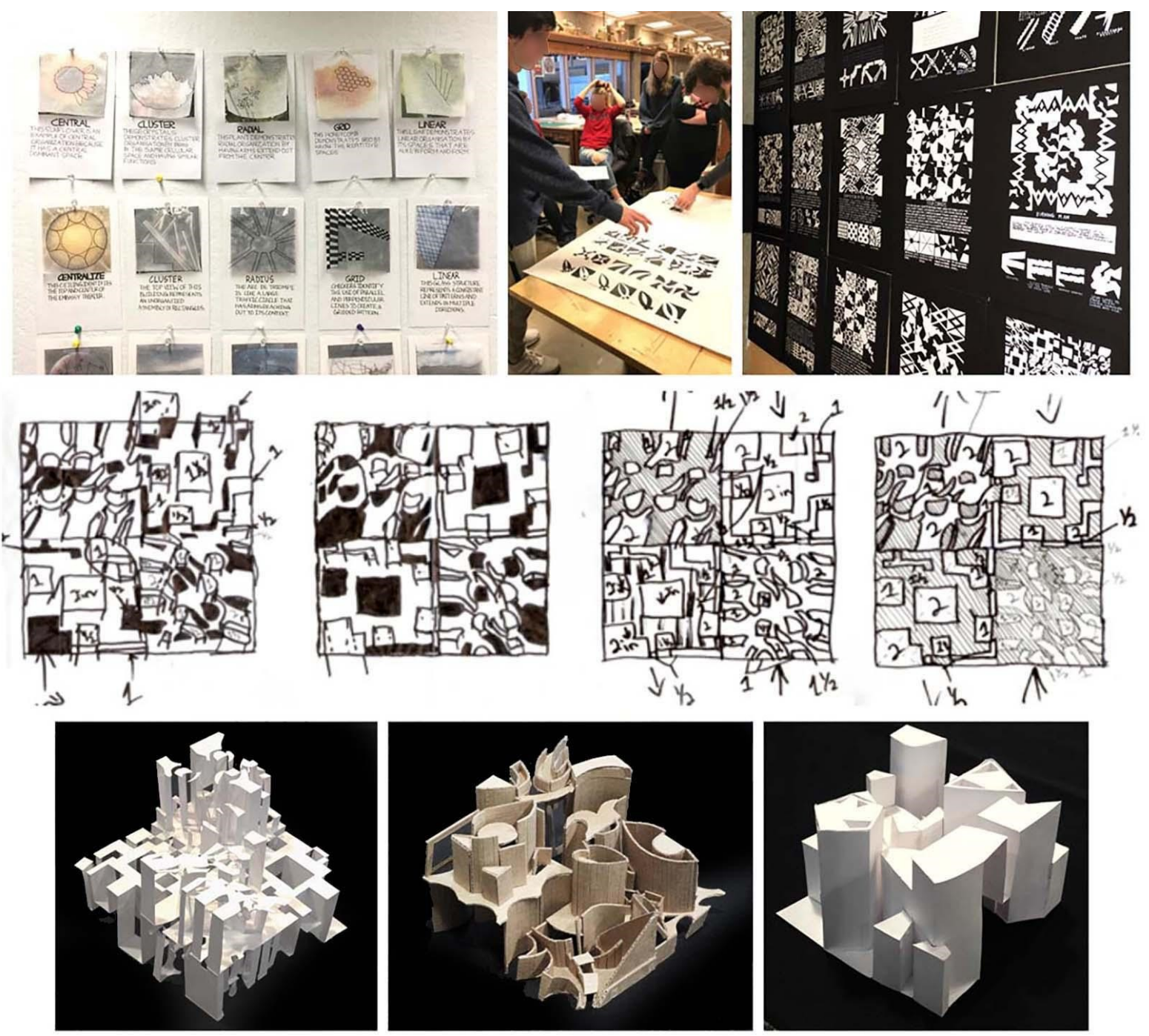

Figure 3 A design journey from precedent image to abstraction, manipulation, collaboration, critique, two-dimensional composition, and three-dimensional extrusions of mass, plane and void (Source: Authors, 2019).

\section{Project Three: Operative Moves Informing the Process of Making}

The game of chess is one of the most recognizable products of civilization. Students were challenged to examine how the typology of pieces, the game-board and the rules associated with the game of chess could potentially inform the creation of a new chess set much like the creation of a metropolitan city skyline over a period of time. The meaning of these individual expressions then could be read as part of the meaning of a collective whole, and a city's overall visual and physical identity. Students were introduced to a brief history of chess sets, ranging from archaeological findings dating from twelfth-century Scotland, with designs that were largely anthropomorphic, through to the nineteenth-century legacy of British chess champion Howard Staunton, who endorsed the baluster-inspired, tripartite design of the sets we use today. ${ }^{14}$ 
Students were then assigned to perform literature and image reviews of three different sets across history. Popular finds included the 1924 Bauhaus workshop set by Josef Hartwig. ${ }^{15}$ Students chose Hartwig's set for its reflection of the chess moves in the composition and form of the pieces. Among other sets chosen were designs by Frank Gehry for Tiffany, ${ }^{16}$ citing interest in the formal interpretations of the pieces' identities, including each pawn sharing a common vocabulary without being identical. Students also explored sets from non-western settings and cultures.
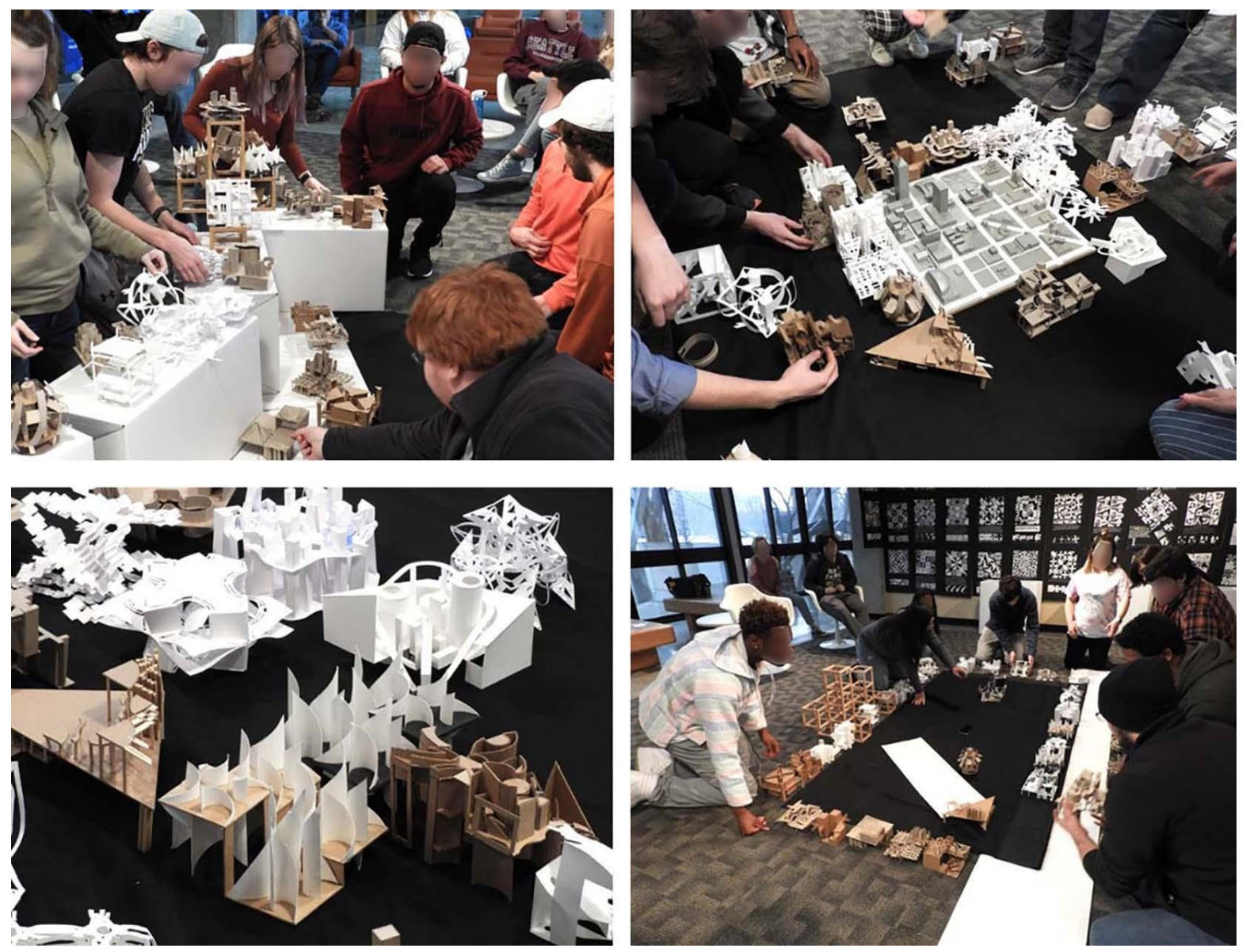

Figure 4 A process of discovery continues through a team-building exercise in which individual three-dimensional compositions come together to form model cities based on ordinance, a catalyst, or by a mocked-up geographic condition (Source: Authors, 2019).

\section{Precedent Study to Fabrication}

During the literature and image review, students were asked to sketch a variety of details, forms, concept sketches and pictorial interpretations from their inquiry. Students then constructed a half set of pieces, using the recommended materials of wooden dowel rod in a square profile, or other forms of dimensional lumber. Angled cuts of 30, 45 and 90 degrees allowed for an operative connection to the assigned moves of the various chess pieces. For example, the rook can only move 90 degrees, and the bishop can only move 45 degrees. An emphasis on the look and feel of the pieces and whether interpretations would be recognized in game play were discussed as necessary design criteria. Students were also asked to consider and diagram the assigned move behaviour of each piece (Figure 5). 

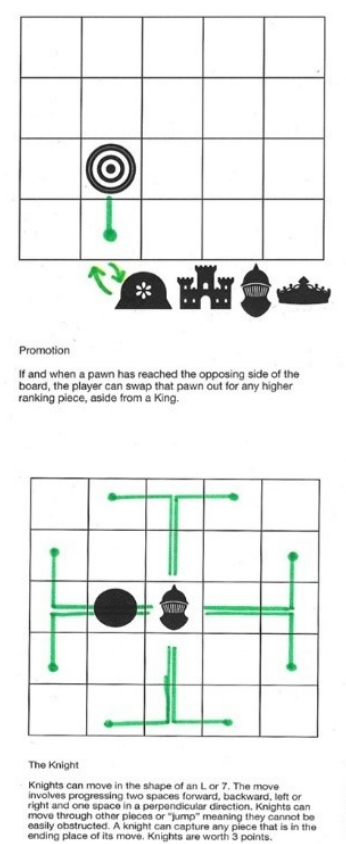
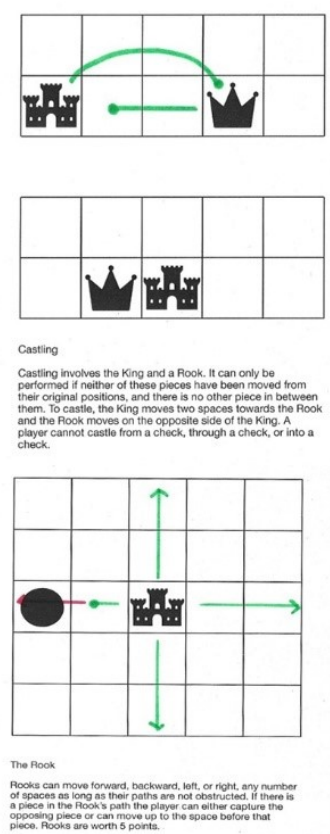
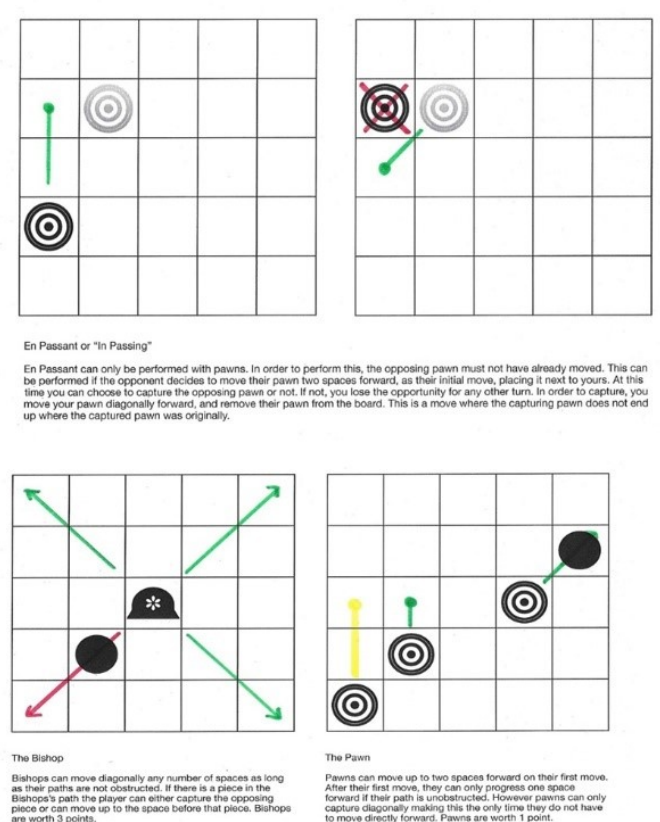

Figure 5 Students were challenged to diagram and analyse the behaviours of individual pieces and traditional moves in the game of chess to generate a typology of operations for design and fabrication of an original half set (Source: Emilee Lemmer, 2019).

Such challenges, interpretations and learning opportunities were imbued into the students' design process throughout the course of the project. One observation that emerged from the collective effort was the notion that the design and making of a functional chess set is a 1:1 expression of both form and function. This is arguably a difference from the majority of projects in beginning environmental design education that dwell solely in the form of scale models and representative drawings. The authors shared a 2003 quote from Steve Jobs, co-founder of Apple Computer, Inc.: 'Most people make the mistake of thinking design is what it looks like ... That's not what we think design is. It's not just what it looks like and feels like. Design is how it works. ${ }^{17}$

The necessary testing and evaluation through the historical and cultural lens associated with the game of chess allowed the student learners to test if their designs worked according to the physical relationship of form and function, while challenging the culturally accepted norm associated with an everyday chess set's product design. The design of the Staunton set that we use today is informed by elements in architecture, but it arguably has not changed for the consumer in centuries. Discussion of the parallels between this widely accepted cultural norm and the design of landmarks, skyscrapers and city skylines was palpable, allowing students and faculty to begin thinking about design across several scales, prior to a field trip to Chicago to experience an urban context and dialogue of tall buildings.

\section{Testing Design Decisions through the Framework of Game Play}

A group-wide chess event was held to test the effectiveness of the sets as functional objects. This opportunity allowed students to evaluate the durability, recognition and practicality of their designs. Functional and physical properties such as object weight, sturdiness, object feel and centre of gravity were observed and critiqued through the actions of game play. For example, pieces with a lower centre of gravity tended to feel good in the hand and not topple over. Culturally informed object recognition, i.e. did the piece identify as its intended rank at the beginning and during game play, became a good question to examine. For example, if a player could not remember what a bishop looked like, it could slow or stop game play entirely. As a final step, students then made a set of patent office-style drawings to depict the designed pieces in a recognizable graphic format in plan and elevation views to scale (Figure 6). This portion of the project allowed the authors to reinforce the processes of thinking through drawing and 
the orthographic conventions of architectural drawing and connect the student learners to a larger tradition of design and fabrication communication as used by the US Patent Office. ${ }^{18}$

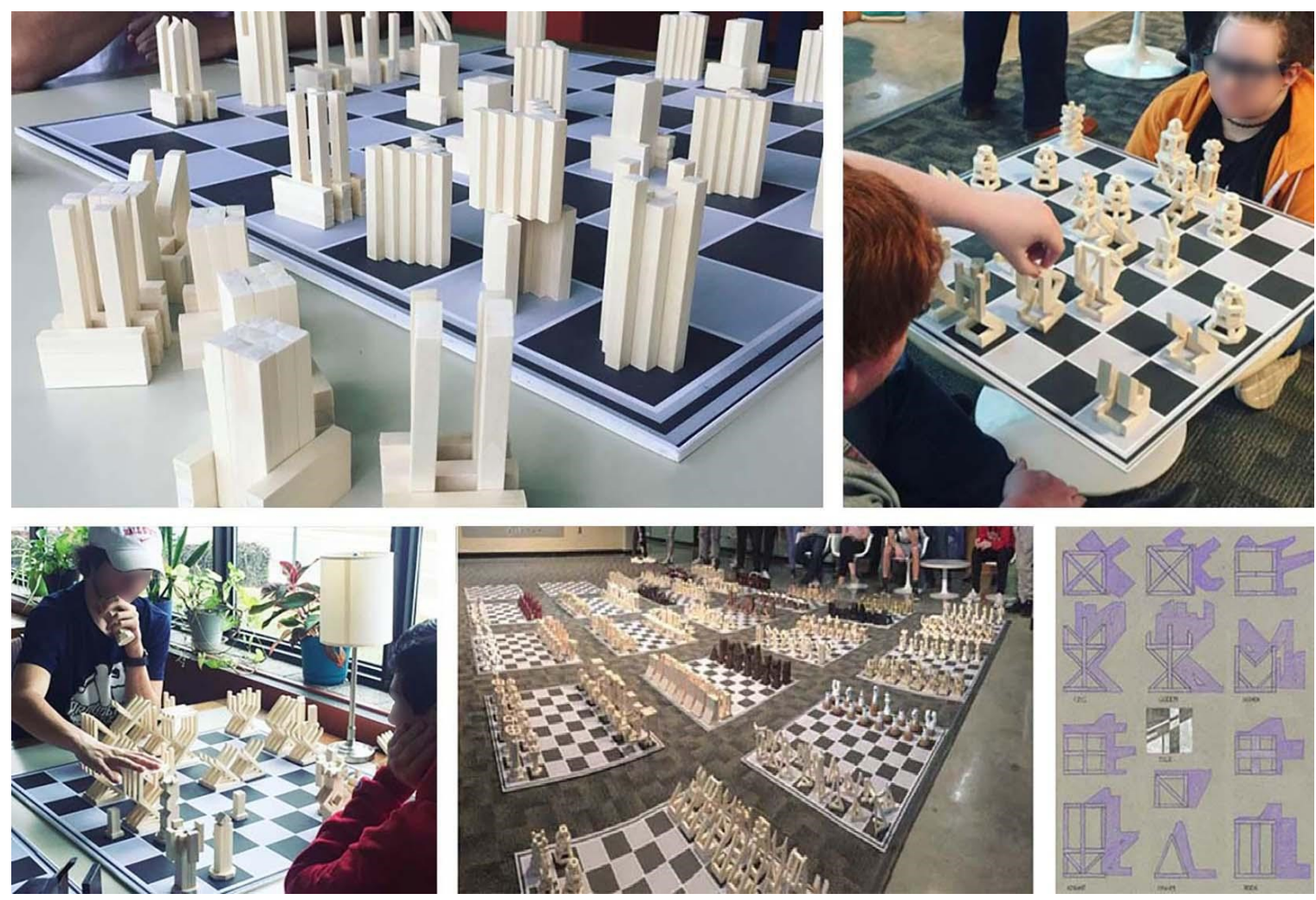

Figure 6 A studio-wide chess event tested the effectiveness of designs and invited college-wide participation. Patent office-style drawings recorded designs in plan and elevation views at full scale and recalled a tile design from the previous unit (Source: Authors, 2019).

\section{Project Four: Application to a Real Site}

Much of the first semester of this design experience exists in abstraction and metaphor. To close the semester, it has been opined by the curriculum oversight committee over the years that the students consider the importance of testing a design vocabulary against the issues and constraints of a real site. A premier natural and ecological feature of Muncie, Indiana, is the White River, a body of water that physically and socially divides the city, has a celebrated history of post-industrial clean-up, and has historic and cultural relevance to generations of native people. It also gave the students the opportunity to study the dynamics of flooding in a context of climate change and a topographic condition to review vertical and horizontal circulation for humans, initially examined in the first project with a table tennis ball.

\section{Site Inventory and Analysis}

Student teams began the project with inventory and analysis in the form of mapping, diagramming and drawing on site. Consideration of the river as a corridor of recreational amenities, including neighbourhood connections, enhanced student awareness and empathy for distressed neighbourhoods in the city. Considerations for disabled access, canoe and kayak launching, safety lighting, seating and conveniences add to the checklist of facilities and amenities currently lacking along the corridor. Teams collected these considerations into a master plan in graphic form for critique and review.

\section{Site Intervention}

Following the team exercise, students chose an individual site for a detailed design opportunity through the lens of placemaking. Review of previous design vocabulary - through the ordering systems 
of the tile project, the circulation systems of the table tennis ball and the landmark or public art potential of a chess piece at a monumental scale - form the logical catena for the design of this final project. Programmatically and spatially, discussions of typology and taxonomy continued in the form of recommended manifestations of promontory, threshold, belvedere, promenade, shelter and an event space for playing lawn chess or table chess.

A review of the spatial verbs as defined by Serra, and ordering systems as defined by Ching, also continued in the students' design process as these words had become a natural part of the dialogue and vocabulary at this point in the semester. A two-hour design charrette challenged the students to review their earlier tile project design as a catalyst for a folded surface that could then be imagined as a design concept for a park pavilion or shelter. While few students used this rapidly delineated design idea in their final project, it was voiced that the charrette challenged their preconceived notions of space and form (Figure 7). Final scale drawings and models showing the completed project were displayed in the main lobby of the college facility at the bequest of the college dean. The observed aptitude, creativity, work ethic and achievement of this particular cohort was thus shared with the entire college community and incoming freshman orientation visitors.
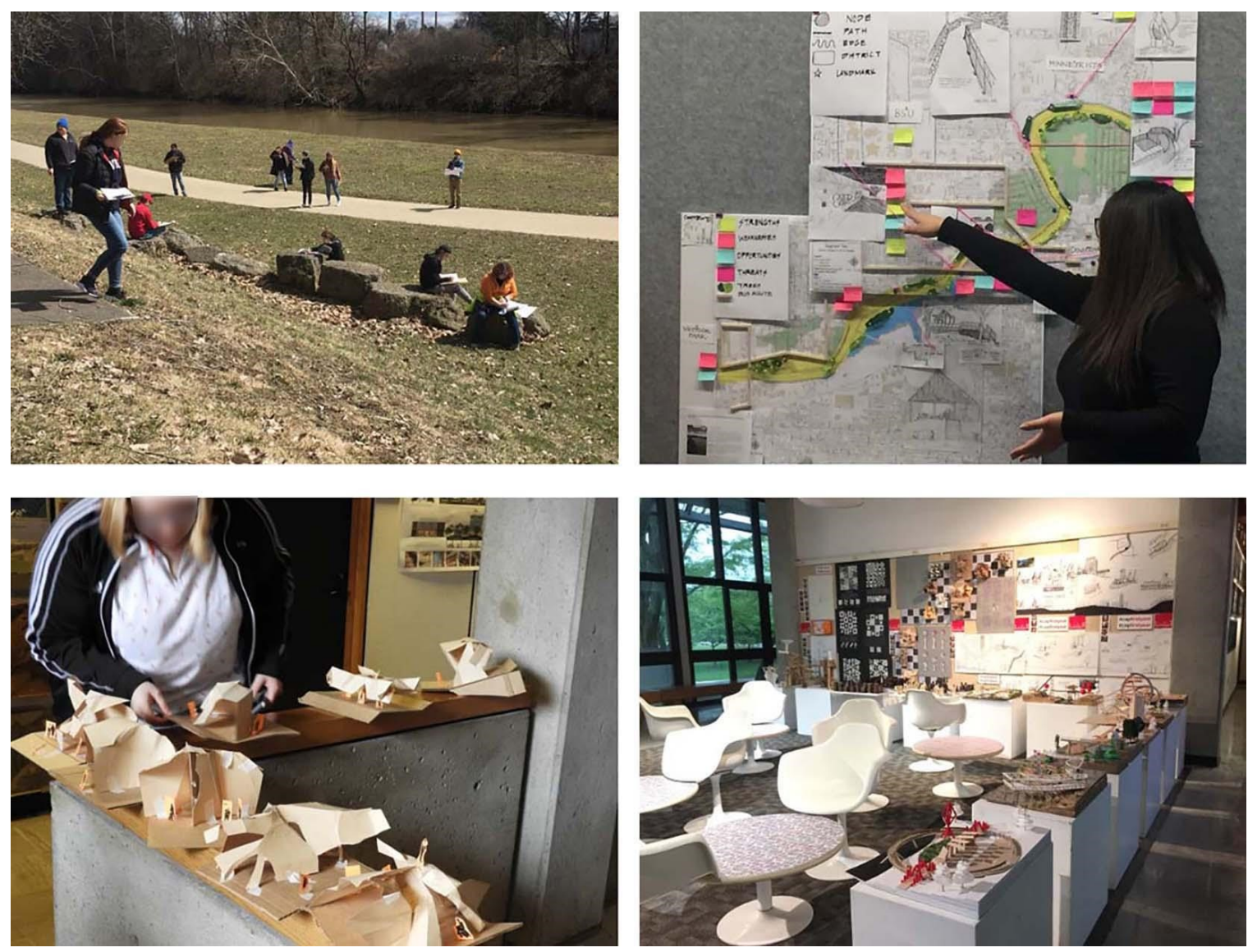

Figure 7 The final semester project began with site inventory along a river levee corridor, continued with a group master plan and a study model charrette and ended with an exhibition of work (Source: Authors, 2019).

\section{Findings and Application of Concrete Experiences}

In reflection, the instructor team observed the potential of catena-based thinking to be a good representation of Kolb's experiential learning theory. Kolb's theory is summarized in four stages and described using the studio-based learning model featured in this article (Figure 8). The first stage is termed as concrete experience. ${ }^{19}$ This introductory stage is where the student actively experiences an activity such as a studio workshop session or a field study. Design education that uses the collaborative studio arguably welcomes this structure across active learning models. The second stage is reflective observation, or an 
opportunity for the student to consciously reflect on the previous experience. Studio-based courses that use the critique or review process in the form of a gallery opening or juried review facilitate a structured reflection for the student. As Angela Passarelli and David Kolb summarize in their 2011 article and 2020 revised working paper entitled The Learning Way: Learning from Experience as the Path to Lifelong Learning and Development:

Immediate or concrete experiences are the basis for observations and reflections. These reflections are assimilated and distilled into abstract concepts from which new implications for action can be drawn. These implications can be tested and serve as guides in creating new experiences. The learning cycle is a recurring circular process as opposed to the linear, traditional information transmission model of learning used in most education where information is transferred from the teacher to the learner ... In the cycle of learning learners receive information through experiencing and transform it by reflecting and thinking and then transform it again by acting to change the world. They are both receivers and creators of information. ${ }^{20}$

It is this dynamic that gives great meaning to project-based learning, design-thinking activities and the architectural design studio model as a basis for practical problem-solving education moving forward, and perhaps why the design studio has such a profound impact on alumni who have experienced it. Skills in analytical judgement, conceptualization of new products and processes and the ability to communicate these ideas and potentials both verbally and graphically are endemic to the studio and give learners great agility in their professional and social lives.

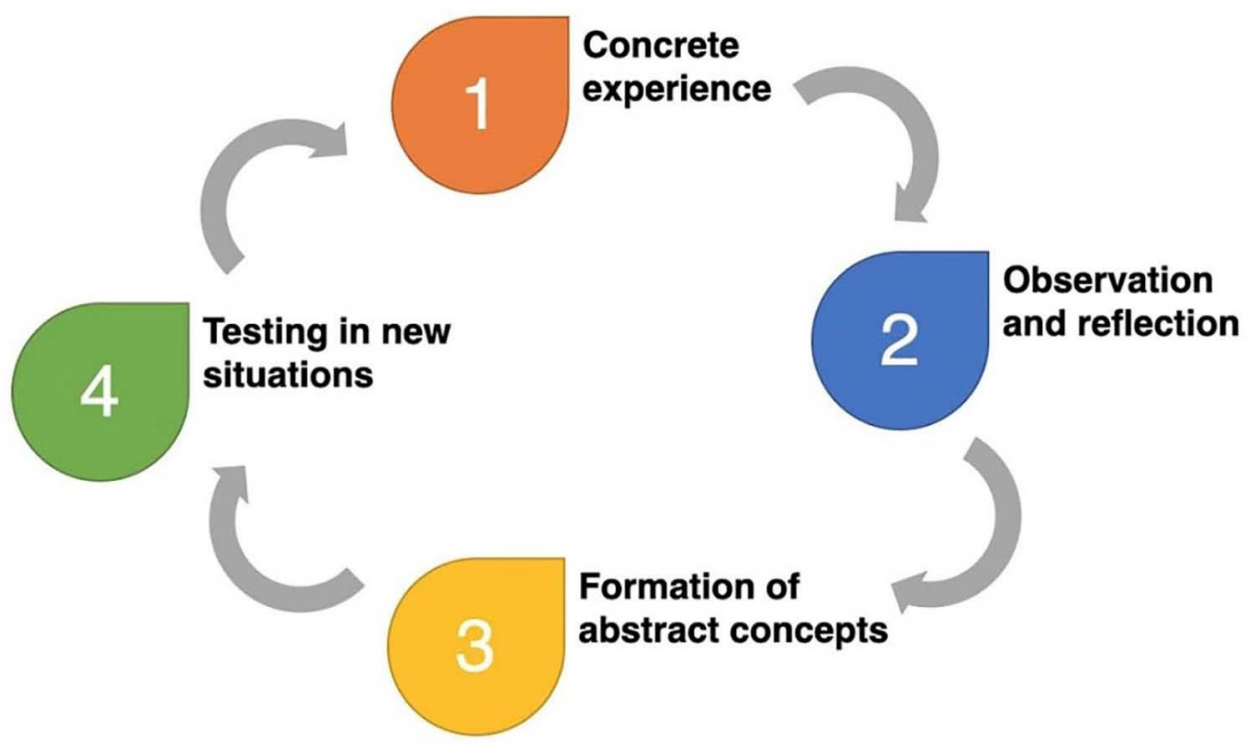

Figure 8 Visualization of Kolb's experiential learning cycle (Source: Lohren Deeg, 2019, derived from Kolb). ${ }^{21}$

\section{Testimonials and Reflection}

Student Autumn Patrick referred to how multiple constraints and drivers helped direct her thinking. She wrote:

The work done in [projects] 1-3 helped me change the way I look at a project [or] idea. Using the [Ching] organizing systems helped me design my [chess] pieces with level bases and similar structural walls throughout my pieces. I enjoyed using the verbs to look at a project differently. I hope that this project is done in the future. ${ }^{22}$ 
Students Lucas Becker and Sofia Gallo reflected on the aesthetic expectations of a chess set as well as the necessary discipline and iterations found in a typical design process. As the introduction to this article indicates, the authors found that students like to do things just once. Required iterations imposed on the project timeline help address this tendency. Becker shared:

[In the course of the chess project] I learned that consistency is very important in a project like this because the chess pieces all needed to have a similar theme in order for it to be unique and stand out. The past units taught me that being prepared and having sketches or models can help a lot when it comes to the final design. With my chess pieces I changed my designs three times until I was satisfied with them. ${ }^{23}$

Gallo shared that '[Projects 1 to 3] helped me think outside the box rather than stick to preconceived ideas of what something should look like as opposed to what it might look like'. ${ }^{24}$

Student Molly Page shared the following insights on working in small groups, addressing the problems of resistance to doing tasks more than once, as well as the observed reticence of sharing thoughts in groups:

Working as a part of a group in the context of a studio class setting is a new experience for me. Typically, in the past whenever I was put in a group for a project, we would split it into equal parts and bring it together right before the deadline. My group and I quickly realized that this is not a viable method for this project. We started off by splitting up the work into sections, but we quickly learned that with studio projects that require lots of trial and error this does not work. We were constantly asking each other for input, so we eventually just ended up working together on all of it. Our group specifically meshed together really well. All of our personalities and work ethics are somewhat similar, yet we all have differences that allowed us to have unique viewpoints and ideas. There were times when we disagreed on things, but every time we were able to come to an agreement after some discussion. Overall having this experience has been very beneficial to me. Having a project where I am able to bounce my ideas off of other people while I simultaneously give feedback on theirs is a great learning opportunity. Since all group members were working on the same project, we all had the same goal and were all equally dedicated. This made the project an interesting experience. ${ }^{25}$

Page has revealed a great deal of the current dynamics of diverse American students working in groups. In the academic years of 2019-2020, Ball State welcomed a significant number of first-generation college students. Differences in ethnic background, social class, home neighbourhoods and perceptions of the built environment shaped this group dynamic. Digital communications at times enhanced it and sometimes detracted from it. As Page indicated, a series of trial-and-error-based activities became necessary to both complete the project and shape the group's communication. In the end, they were able to sort things out.

Trial and error is arguably a necessary process to arrive at a design solution that is informed by multiple iterations and trials. Inevitably, one has to learn to let go. Student Kaitlyn Gobrogge shared some reflections on the lessons of letting go and moving on to another concept. She wrote about the project units in sequence:

Units 1-3 helped me work my way through Unit 4 more effectively. Unit 1 helped me figure out that I needed to be resourceful and that even if I didn't have the materials for my design that I could still make it beautiful. Ping taught me that I need to commit to an idea and keep trying to find a solution, but also to always have a backup plan and know when to let the idea die. Unit 3 showed me that I shouldn't let my stubbornness get in the way because it will greatly hinder my progress of design and craft. Overall the previous three units taught me that I need to be open to multiple ideas and test all of them. It allowed me to be open to the idea of changing my design when the materials/restrictions didn't work in my [favour]. ${ }^{26}$ 


\section{Remediation}

In the authors' experience, the four stages of Kolb's sequence would end at the third stage and lack the enrichment of the fourth. It is with this study that the authors arguably remedied this deficiency. The fourth stage, active experimentation, allowed the design student to develop a method to test a model or theory or plan for a forthcoming experience. Applying the idea of a catena to the projects allowed for multiple instances of reflection and testing of a design idea as applied to a real site in the fourth and final semester project, which arguably allows that idea to be applied in a later project or semester (Figures 9 and 10). Catenated thinking thus potentially strengthens a student's design awareness, vocabulary and confidence in the conceptualization and delineation of space and place. In the authors' opinion, the connection of a semester's projects into a cohesive line of thinking can be a good model for interdisciplinary and collaborative teaching well into the future. In Table 1, the authors restate the key problems observed at the beginning of the article, connect them to principles of Bruner's spiral curriculum or Kolb's experiential learning cycle, and finally compare them with an example of studio pedagogy.
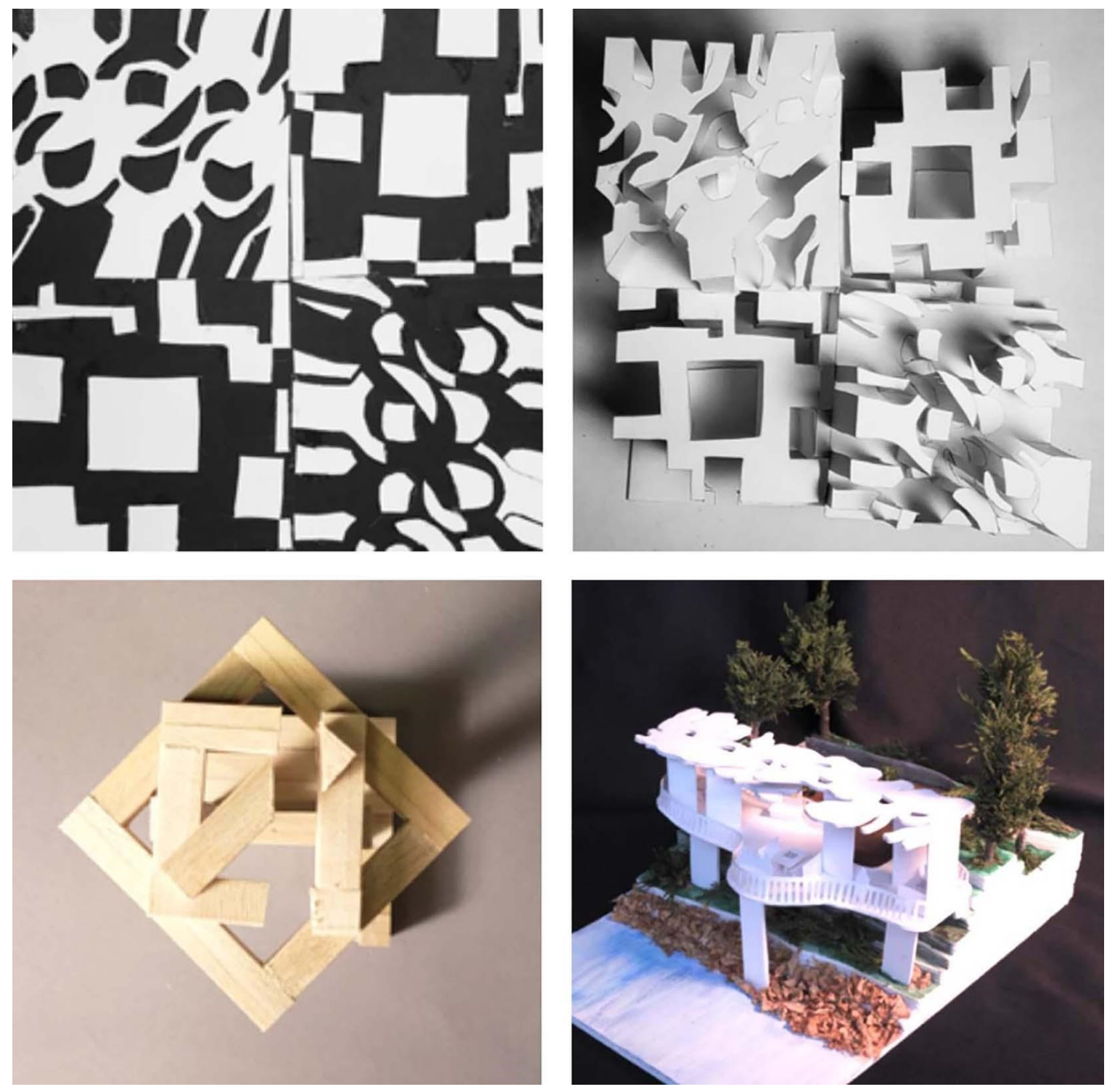

Figure 9 An example of one student's semester work informed by the concept of catena, or a series of connected activities. Patterns in positive and negative space emerged from two to three dimensions, into a wooden chess piece, and finally as a belvedere along an urban riverfront (Source: Work by Alison Janik, photographs by Authors, 2019). 
Table 1 Observed problems against Bruner, Kolb and resulting pedagogy.

Kolb Principle $\quad$ Studio Pedagogy

\begin{tabular}{l}
\hline Problem Observed \\
\hline Student learners tend to \\
prefer to perform an activity \\
of design or making only \\
once rather than naturally \\
accept multiple options or \\
explorations as divergent \\
thinking activities in design \\
thinking often demand
\end{tabular}

thinking often demand

Bruner Principle
'An educated man must not
be dazzled by the myth that

zled by the myth that advanced knowledge is the result of wizardry. The way to battle this myth is in the direct experience of the learner - to give him the experience of going from a primitive and weak grasp of some subject to a stage in which he has a more refined and powerful grasp of it ${ }^{27}$

\section{Creative and frequent}

application of all four stages

Concrete experiences in

haptic crafting and making, as

well as visiting spaces

and places

Frequent opportunity for

observation and reflections

Forming and examining

application of

abstract concepts

Testing and critiquing the success or failure of environmental design solutions

\begin{tabular}{ll}
\hline Learners tend to be & 'Bruner thought highly of \\
distracted by digital content & participatory methods or \\
via their mobile devices & models of learning, rather \\
& than the mere receiving of \\
& information, knowledge, or \\
& skill' 28
\end{tabular}

Students are exhibiting a lack of curiosity or critical thinking of why things are the way they are

'Education must, then, be
not only a process that
transmits culture, but also
one that provides alternative
views of the world and
strengthens the will to
explore them' 29

'Subjects and topics must be

The access to free, open, unlimited information has instituted a form of what we will term digital amnesia or the tendency to not retain or synthesize new information, nor be curious in acquiring or retaining information, as information is always just a click away presented according to the structures of the academic disciplines which are the essence and reflection of accumulated human curiosity ${ }^{30}$

'learning is no longer seen as merely a matter of the mastery of the content; it is a set of phenomena that occurs around the mastery of the content ${ }^{31}$

\section{Facilitate concrete}

experiences interacting with

the social, natural and constructed environments, and build a common vocabulary and critical discourse of architecture and planning

Build a rigorous and
disciplined routine of
new situations and opportunities for critique and reflection

\section{Facilitate concrete} experiences interacting with the social, natural and constructed environments, and engage learners in sharing their work as part of a larger critical discourse that propels them into professions that are charged with defending the public interest and the health of the planet

Design projects and lesson

plans that build on one another, remind students of past learning experiences, use artefacts of past projects as iterative pieces in new projects

Periodic reminders of why certain teaching methods are used or what is gained from doing a project a certain way Communicate and show over the timeline of a semester that activities and projects build on one another

\section{Enforce a mandatory or} required stowage of devices during studio time or use the mobile device as a tool in a daily learning activity or project Initiate peer-review critique activities that involve writing commentary on real or virtual sticky-notes, require reflective statements at the end of projects, make hallway pin-ups and critiques more active

\section{Reinforce the discipline and} process of architectural (and allied) design as a study of form space and order as defined by Francis D. K. Ching. The chapter sequence does work as a framework for learning objectives as opposed to cherry-picking from the textbook

Facilitate activities such as a crowd-sourced literature review with a flip chart or concept board, building data-mining skills and critical thinking of sources, and building familiarity with trusted sources germane to professions

A tendency for students to
share ideas, critiques and
processes individually or in
small groups of two to six
persons, but not in
large groups

'education tends to work well when learning is, first, participatory, provocative, communal, and collaborative; and second, when learning is a process of constructing meaning rather than receiving, 32

\section{Facilitate concrete} experiences interacting with the social, natural and constructed environments, in the spirit of social awareness, responsibility, collaboration and team building

\section{Initiate peer review critique} activities that involve writing commentary on real or virtual sticky-notes, require reflective statements at the end of projects, make hallway pin-ups and reviews more active 

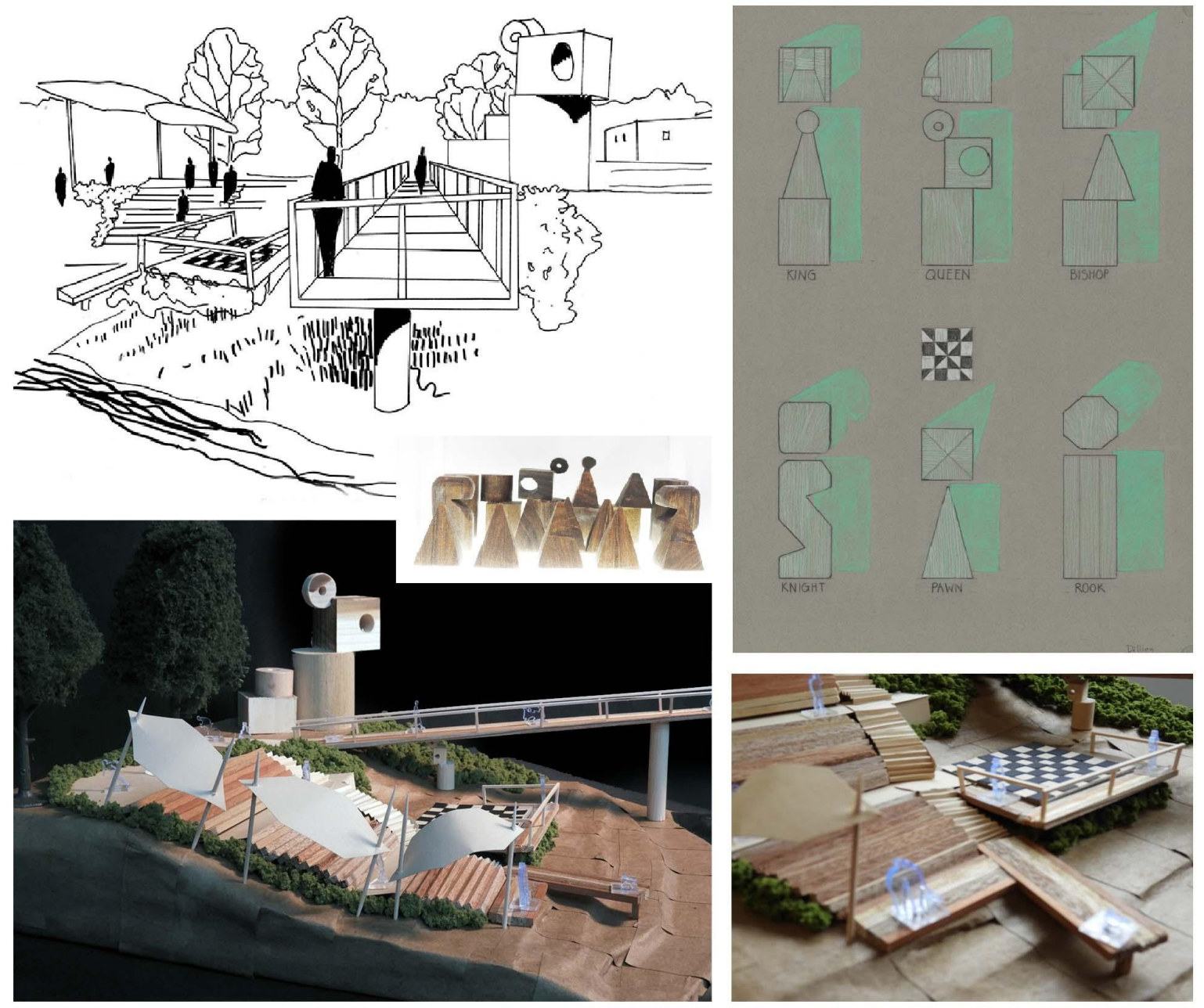

Figure 10 An example of one student's semester work informed by the concept of catena, or a series of connected activities. The queen piece from a designed chess set emerges into a landmark sculpture overlooking two jetties, a seating area and an outdoor chess play deck (Source: Work by Dillon Redding, photographs by Authors, 2019).

\section{Conclusion}

It is important, as Kolb argues, to reflect on the why. Together the three authors of this article represent nearly 50 years of teaching from K-12 primary education to graduate-level studios and advising. The immediacy of the issues examined here in seeing the differences in the behaviours and attitudes of freshman-level entry students necessitate some sort of reboot. The stress, traumas and anxieties that have been imparted on their lives are palpable and will continue to affect their learning experiences. Generation $\mathrm{Z}$ is one that has witnessed deployed US. military action for the entirety of their time on earth, an exponential growth in artificial intelligence, a global pandemic, two economic recessions, a changing climate, the decline of expertise, continued racial injustice and social inequality. To meet these students at their level remains critically important as all of these issues will continue to be discussed, tested and ultimately manifested in the constructed environment and the public realm. Not only is it responsible to critically reflect on design education, it is necessary for it to remain relevant and not ignored or replaced by the hubris of data engines motivated and informed by a single bottom line. Humanity will continue to build. The question will be if a critical and educated mind will be able to do it well.

\section{Acknowledgements}

The authors wish to thank Christine Rhine, Graduate Assistant Kiya Mullins, and the students of the CAPFY Spring admission class of 2019. 


\section{Declarations and Conflict of Interests}

The authors declare no conflict of interests with this work.

\section{Notes}

${ }^{1}$ Merriam-Webster, 'Catena'.

${ }^{2}$ Serra, 'Richard Serra. Verblist'.

${ }^{3}$ Bruner, 'On Knowing', as cited in Takaya, 'Jerome Bruner's Theory of Education'; Kolb, Experiential Learning, 31.

${ }^{4}$ Fry and Parker, "Post-Millennial" Generation'.

${ }^{5}$ Silverman, 'Lies, Damn Lies and Viral Content'.

${ }^{6}$ Lukianoff and Haidt, 'How Trigger Warnings Are Hurting Mental Health on Campus'.

${ }^{7}$ Merriam-Webster, 'Catena'.

${ }^{8}$ Serra, 'Richard Serra. Verblist'.

${ }^{9}$ Ching, Architecture, 194-239.

${ }^{10}$ Bruner, On Knowing.

${ }^{11}$ Serra, 'Richard Serra. Verblist'.

${ }^{12}$ Ching, Architecture.

${ }^{13}$ Ching, Architecture.

${ }^{14}$ Bailey and Allred, 'The Staunton Standard'.

${ }^{15}$ Hartwig, 'Josef Hartwig. Chess Set'.

${ }^{16}$ Liszewski, 'Frank Gehry's Tiffany Chess Set'.

${ }^{17}$ Walker, 'The Guts of a New Machine'.

${ }^{18}$ Chang, 'The History (And Artistic De-Evolution) of Patent Drawings'.

${ }^{19}$ Kolb, Experiential Learning, 32.

${ }^{20}$ Passarelli and Kolb, 'The Learning Way', 6.

${ }^{21}$ Kolb, Experiential Learning, 31-2.

${ }^{22}$ Patrick, 'Journal Reflection'.

${ }^{23}$ Becker, 'Journal Reflection'.

${ }^{24}$ Gallo, 'Reflection on Past Units'.

${ }^{25}$ Page, 'Project Reflection'.

${ }^{26}$ Gobrogge, 'Past Projects'.

${ }^{27}$ Bruner, On Knowing, 109.

${ }^{28}$ Bruner, On Knowing, 18.

${ }^{29}$ Bruner, On Knowing, 7.

${ }^{30}$ Bruner, On Knowing, 6.

${ }^{31}$ Bruner, On Knowing, 13.

${ }^{32}$ Bruner, On Knowing, 15.

\section{References}

Bailey, Shannon, and Emily Allred. 'The Staunton Standard: Evolution of the Modern Chess Set. World Chess Hall of Fame'. Accessed 31 October 2018. https://worldchesshof.org/exhibit/stauntonstandard-evolution-modern-chess-set.

Becker, Lucas. 'Journal Reflection', 22 March 2019 (personal communication).

Bruner, Jerome S. On Knowing: Essays for the Left Hand. Cambridge, MA: Belknap Press, 1997.

Chang, Alexandra. 'The History (and Artistic De-Evolution) of Patent Drawings'. Wired, 8 January 2012. Accessed 20 June 2018. https://www.wired.com/2012/08/the-history-and-artistic-degredation-ofpatent-drawings/.

Ching, Francis D. K. Architecture: Form, Space, and Order. Hoboken, NJ: John Wiley and Sons, 2015. 
Fry, Richard, and Kim Parker. "Post-Millennial" Generation on Track to Be Most Diverse, Best-Educated'. Pew Research Center's Social \& Demographic Trends Project, 15 November 2018. Accessed 30 May 2020. http://www.pewsocialtrends.org/2018/11/15/early-benchmarks-showpost-millennials-on-track-to-be-most-diverse-best-educated-generation-yet/.

Gallo, Sofia. 'Reflection on Past Units', 22 March 2019 (personal communication).

Gobrogge, Kaitlyn. 'Past Projects', 22 March 2019 (personal communication).

Hartwig, Josef. 'Josef Hartwig. Chess Set. 1924: MoMA'. The Museum of Modern Art. Accessed 27 May 2020. https://www.moma.org/collection/works/4240.

Kolb, David A. Experiential Learning: Experience as the Source of Learning and Development. Upper Saddle River, NJ: Pearson Education, 2015.

Liszewski, Andrew. 'Frank Gehry's Tiffany Chess Set is a Miniature Architectural Marvel'. Gizmodo. Accessed 17 June 2013. https://gizmodo.com/frank-gehrys-tiffany-chess-set-is-aminiature-architect-5905941.

Lukianoff, Greg, and Jonathan Haidt. 'How Trigger Warnings are Hurting Mental Health on Campus'. The Atlantic. Accessed 31 July 2017. https://www.theatlantic.com/magazine/archive/2015/09/thecoddling-of-the-american-mind/399356/.

Merriam-Webster, s.v. 'Catena (n.)'. Accessed 1 June 2020. https://www.merriam-webster.com/dictionary/ catena.

Page, Molly. 'Project Reflection', 28 February 2020 (personal communication).

Passarelli, Angela M., and David A. Kolb. 'The Learning Way: Learning from Experience as the Path to Lifelong Learning and Development'. In The Oxford Handbook of Lifelong Learning, edited by Manuel London, 69-90. Oxford: Oxford University Press, 2011. https://doi.org/10.1093/oxfordhb/ 9780195390483.013.0028.

Patrick, Autumn. 'Journal Reflection on Units 1-3', 22 March 2019 (personal communication).

Serra, Richard. 'Richard Serra. Verblist. 1967-68: MoMA'. The Museum of Modern Art. Accessed 1 June 2020. https://www.moma.org/collection/works/152793.

Silverman, Craig. 'Lies, Damn Lies and Viral Content'. Academic Commons, 2015. Accessed 5 September 2017. https://academiccommons.columbia.edu/doi/10.7916/D8Q81RHH.

Takaya, Keiichi. 'Jerome Bruner's Theory of Education: From Early Bruner to Later Bruner'. Interchange 39(1) (2008): 1-19. [CrossRef]

Walker, Rob. 'The Guts of a New Machine'. New York Times, 30 November 2003. Accessed 30 November 2003. https://www.nytimes.com/2003/11/30/magazine/the-guts-of-a-new-machine.html. 